\title{
The factors associated with longitudinal changes in liver stiffness in patients with chronic hepatitis B
}

\author{
In Ku Yo, Oh Sang Kwon, Jin Woong Park, Jong Joon Lee, Jung Hyun Lee, In Sik Won, Sun Young Na, Pil Kyu Jang, \\ Pyung Hwa Park, Duck Joo Choi, Yun Soo Kim, and Ju Hyun Kim
}

Division of Gastroenterology, Department of Internal Medicine, Gachon University Gil Hospital, Incheon, Korea

Background/Aims: Liver stiffness (LS) as assessed by transient elastography (TE) can change longitudinally in patients with chronic hepatitis B (CHB). The aim of this study was to identify the factors that improve LS.

Methods: Between April 2007 and December 2012, 151 patients with CHB who underwent two TE procedures with an interval of about 2 years were enrolled. Ninety-six of the 151 patients were treated with nucleos(t)ide analogues [the antiviral therapy (+) group], while the remaining 55 patients were not [the antiviral therapy (-) group]. The two groups of patients were stratified according to whether they exhibited an improvement or a deterioration in LS during the study period (defined as an LS change of $\leq 0$ or $>0 \mathrm{kPa}$, respectively, over a 1-year period), and their data were compared.

Results: No differences were observed between the antiviral therapy (+) and (-) groups with respect to either their clinical characteristics or their initial LS. The observed LS improvement was significantly greater in the antiviral therapy $(+)$ group than in the antiviral therapy (-) group $(-3.0 \mathrm{vs.} 0.98 \mathrm{kPa}, P=0.011)$. In the antiviral therapy (+) group, the initial LS was higher in the LS improvement group ( $n=63)$ than in the LS deterioration group ( $n=33 ; 7.9$ vs. $4.8 \mathrm{kPa}, P<0.001)$. However, there were no differences in any other clinical characteristic. In the antiviral therapy (-) group, the initial LS was also higher in the LS improvement group ( $\mathrm{n}=29)$ than in the LS deterioration group $(\mathrm{n}=26 ; 8.3 \mathrm{vs.} 6.5 \mathrm{kPa}, P=0.021)$, with no differences in any other clinical characteristic.

Conclusions: A higher initial LS was the only factor associated with LS improvement in patients with CHB in this study. (Clin Mol Hepatol 2015;21:32-40)

Keywords: Chronic hepatitis B; Hepatic fibrosis; Liver stiffness; Transient elastography

See Editorial on Page 22

\section{INTRODUCTION}

Chronic hepatitis $B(C H B)$ is a chronic liver inflammation that creates fibrous tissue and leads to architectural distortion of the liver. If liver fibrosis progress to cirrhosis, complications arising from portal hypertension and functional hepatocyte loss develop. Furthermore, decompensated liver cirrhosis and hepatocellular carcinoma, the end points of liver fibrosis, directly threaten life. However, liver fibrosis is thought to be reversible if optimal man-

\section{Abbreviations:}

$A L T$, alanine aminotransferase; $C H B$, chronic hepatitis $B ; C H C$, chronic hepatitis $\mathrm{C} ; \mathrm{Cl}$, confidence interval; ETV, entecavir; HBV, hepatitis B virus; $\mathrm{HBeAg}$, hepatitis B envelope antigen; HCV, hepatitis C virus; INF, interferon; kPa, kilopascals; LAM, lamivudine; LS, liver stiffness; OR, odds ratio; SVR, sustained virologic response; TE, transient elastography

\author{
Corresponding author: Oh Sang Kwon \\ Division of Gastroenterology, Department of Internal Medicine, Gachon \\ University Gil Medical Center, Gachon Medical School Gil Medical Center, \\ 21, Namdong-daero 774beon-gil, Namdong-gu, Incheon 405-760, Korea \\ Tel: +82- 32-460-3778, Fax: +82-32-460-3408 \\ E-mail:kos@gilhospital.com
}


agement is started timely. The long-term use of oral antiviral agents can reduce liver fibrosis by suppressing hepatitis B virus (HBV) DNA levels and normalizing alanine aminotransferase (ALT) levels in CHB patients in the immune reactive phase. ${ }^{1,2}$ In addition, liver fibrosis is also reduced in CHB patients exhibiting spontaneous regression of the immune reactive state or a persistent inactive HBV carrier state.,

The prognosis of CHB patients is dependent on the extent and rate of progression of fibrosis. Therefore, knowledge of the precise stage of fibrosis is important in the contexts of treatment and determining treatment efficacy. Liver biopsy is considered as the gold standard for estimating degree of fibrosis, but is less than satisfactory for repeat evaluations due to its invasiveness, patients' discomfort, and risk of serious complications $(0.3-0.5 \%)$, including death $(0.03-0.1 \%)^{5,6}$ In addition, a small portion of liver tissue cannot represent the whole liver and the interpretation of results is subject to significant intra- and inter-observer variability. ${ }^{2}$

Accordingly, there is a need for a safe, repeatable non-invasive means of measuring the stage of liver fibrosis. Scoring systems based on serum markers of fibrosis and degree of fibrosis as determined by combinations of several different blood tests have been investigated. ${ }^{7.8}$ However, reported accuracies for the differentiation of moderate and severe fibrosis were not acceptable. In addition, several technical and patient related factors tend to cause under- or overestimations of fibrosis stage.

Several years ago, the FibroScan was introduced for the evaluation of liver fibrosis. It uses an ultrasound-based technique, known as transient elastography (TE), to measure the speeds of propaga- tion of shear waves through the liver, which are directly associated with liver stiffness (LS). ${ }^{9-11}$ The TE technique has several merits as it is rapid, objective, safe, and repeatable. Furthermore, TE measures approximately $1 / 500$ of the liver's total mass, and thus, reduces sampling errors. In addition, the intra- and inter-observation coefficients of variation are $3.2 \%$ and $3.3 \%$, respectively, indicating very good reproducibility. Furthermore, recent reports showed that the measurement of $L S$ by TE accurately predicts the presence of histological fibrosis in patients with liver disease of various etiologies, such as, CHB, chronic hepatitis C (CHC), ${ }^{12-14}$ primary biliary cirrhosis, ${ }^{15}$ and primary sclerosing cholangitis. ${ }^{16}$

Recently, a small number of longitudinal studies on TE examined its repeatability and relation with fibrosis improvement in CHB. ${ }^{1,17}$ Among them, some patients had no improvement of $L S$ in spite of antiviral therapy. ${ }^{17}$ There are few studies about factors that improve LS in patients with CHB. In the present study, longitudinal LS change, presumed to represent hepatic fibrosis, were assessed in CHB patients treated with or without oral antiviral agents and factors associated with improved LS were investigated.

\section{PATIENTS AND METHODS}

\section{Patients}

Between April 2007 and December 2012, 224 patients with CHB underwent TE twice with an interval of about 2 years. A schematic of patient enrollment is provided in Figure 1A. All had

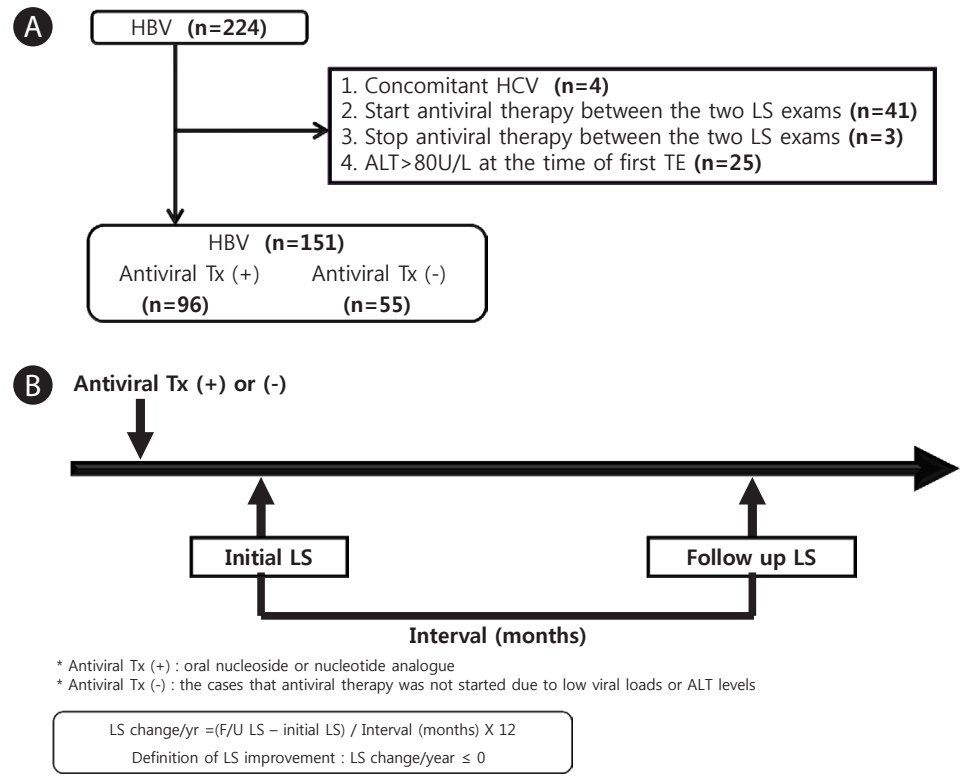

Figure 1. (A) Schematic diagram of patient enrollment. (B) The time point of LS measurements. In the antiviral therapy (+) group, the initial LS measurement was made after serum ALT had decreased to lower than $80 \mathrm{lU} / \mathrm{mL}$. In the antiviral therapy (-) group, the initial LS was measured whenever serum ALT was lower than $80 \mathrm{IU} / \mathrm{mL}$. Follow-up LS was measured at about 2 years after the initial LS. Annual LS changes were calculated by subtracting the follow-up LS value from the initial LS value, dividing the result by the number of months elapsed between the initial and follow-up LS measurements, and then multiplying by 12 . 
hepatitis B surface antigen for more than 6 months. Seventy-three patients were excluded for: 1) concomitant hepatitis C virus (HCV) infection; 2) the initiation or cessation of oral antiviral therapy between the two TE exams; 3) excessive alcohol abuse of over $40 \mathrm{~g} /$ day; or 4) an ALT level of over $80 \mathrm{IU} / \mathrm{mL}$ at the time of first TE. Finally, 151 patients with CHB were included. Ninety-six received oral antiviral therapy, but the other 55 patients were not treated by oral antiviral therapy due to a low HBV DNA level (HBV DNA < 10,000 copies $/ \mathrm{mL}$ in cirrhosis and $<100,000$ copies $/ \mathrm{mL}$ in chronic hepatitis) or a low ALT level (ALT $\leq 40 \mathrm{IU} / \mathrm{mL}$ in cirrhosis and $\leq 80$ $\mathrm{IU} / \mathrm{mL}$ in chronic hepatitis) as directed by the Korean National Health Insurance.

Liver cirrhosis was diagnosed based on clinical, laboratory, and radiologic findings according to clinical practice guidelines. ${ }^{18}$ This study was approved by the Gil Hospital Institutional Review Board (GAIRB2013-211).

\section{LS measurement}

LS was measured by TE (FibroScan ${ }^{\circledR}$, Echosens, Paris) with the patient lying supine with the right arm fully abducted. Measurements were performed over the right lobe of the liver through the intercostal space. At least 10 valid TE readings were taken per patient, and median LS values were used for analysis. Results are expressed in kilopascals (kPa). Performance was considered optimal when the percentage of successful measurements with respect to the total number of acquisitions was at least $60 \%$ and the interquartile range to liver stiffness ratio was less than 0.03 .

For the 96 patients that underwent antiviral therapy [the antiviral therapy (+) group], LS was initially measured when ALT decreased to lower than $80 \mathrm{IU} / \mathrm{mL}$. In the 55 patients without antiviral therapy [the antiviral therapy (-) group], LS was initially measured when ALT was lower than $80 \mathrm{IU} / \mathrm{mL}$. LS was re-measured at about 2 years after initial LS in all 151 patients (Fig. 1B). LS change per year was used to determine whether LS had improved or deteriorated. LS change per year was calculated by subtraction the second $\mathrm{LS}$ value from the first $\mathrm{LS}$ value dividing by the number of intervening months and multiplying by 12 . When the $L S$ change per year was $\leq 0$, LS was considered improved, and if was $>0$ was consider to have deteriorated (Fig. 1B).

\section{Biochemical, hematologic, and virologic examinations}

Routine laboratory tests, including liver function testing, were performed at first TE and then serially at 3-4 month intervals. Hepatitis B envelop antigen (HBeAg) (ADVIA centaur ${ }^{\circledR}$ sp, Siemens Medical Solutions, NY, USA) and HBV DNA levels (m2000 system, Abbott Molecular Inc., Des Plaines, IL, USA) were checked at first $\mathrm{TE}$ and then serially at 6 month intervals.

\section{Statistical analysis}

Statistical analysis was performed using a commercial software package (SPSS, version 13.0, SPSS Inc., Chicago, IL, USA). Values are presented as means \pm standard deviations or as medians and ranges. The analysis was conducted using the Student's $t$-test or the Mann Whitney U-test. Qualitative values are presented as numbers (\%) and analyzed using the chi-square test or Fisher's exact test. LS changes were compared using the paired sample $t$-test. The multivariate analysis was performed using binary logistic regression analysis on variables found to be significant by univariate analysis $(P<0.1)$. $P$-value of $<0.05$ was considered statistically significant.

\section{RESULTS}

\section{Baseline characteristics of the patients}

The pretreatment mean levels of laboratory data in 96 patients who received antiviral therapy [the antiviral therapy (+) group] were AST of $173 \pm 249 \mathrm{IU} / \mathrm{L}$, ALT of $268 \pm 403 \mathrm{IU} / \mathrm{L}$, total bilirubin of $2.1 \pm 3.3 \mathrm{mg} / \mathrm{dL}$, albumin of $3.9 \pm 0.6 \mathrm{~g} / \mathrm{dL}$, platelet count of $173 \pm 77 \times 10^{3} / \mathrm{mm}^{3}$, and HBV DNA of $7.0 \pm 1.2 \log _{10}$ copies $/ \mathrm{mL}$. The first TEs were checked after mean periods of $34 \pm 28$ months after antiviral therapy in the antiviral therapy (+) group.

At the first TE, the antiviral therapy (+) group $(n=96)$ had a higher rate of $\mathrm{HBeAg}(+)$ than the antiviral therapy (-) group $(\mathrm{n}=55)(39.5 \%$ vs. $16.9 \%, P=0.003)$. On the other hand, mean HBV DNA level was higher in the antiviral therapy (-) group than in the antiviral therapy (+) group (4.0 \pm 2.6 vs. $2.7 \pm 2.8 \log _{10}$ copies/ $\mathrm{mL}, P=0.008$ ), because HBV DNA level had already been reduced by antiviral therapy in the antiviral therapy (+) group at first TE. These two groups did not differ in terms of age, gender, prevalence of liver cirrhosis, interval between the two LS exams, or laboratory findings (Table 1).

In the antiviral therapy (+) group, patients were treated by lamivudine (LAM) $(n=49)$, adefovir $(n=12)$, clevudine $(n=4)$, or entecavir (ETV) ( $n=31)$. Among these, 24 patients developed antiviral re- 
Table 1. Comparison of the baseline characteristics of the antiviral therapy (+) and (-) patient groups at first transient elastography

\begin{tabular}{|c|c|c|c|}
\hline & $\begin{array}{l}\text { Antiviral therapy }(+) \\
\qquad(n=96)\end{array}$ & $\begin{array}{l}\text { Antiviral therapy }(-) \\
\qquad(\mathrm{n}=55)\end{array}$ & $P$-value \\
\hline Age (years) & $48 \pm 8$ & $51 \pm 10$ & 0.075 \\
\hline Sex (male, \%) & $71(74)$ & $34(61.8)$ & 0.122 \\
\hline Liver cirrhosis (n, \%) & $28(29.2)$ & $20(36.4)$ & 0.363 \\
\hline AST (IU/L) & $30 \pm 13$ & $32 \pm 11$ & 0.330 \\
\hline $\mathrm{ALT}(\mathrm{IU} / \mathrm{L})$ & $31 \pm 16$ & $34 \pm 17$ & 0.383 \\
\hline GTP $(I U / L)$ & $36 \pm 24$ & $46 \pm 27$ & 0.174 \\
\hline Total bilirubin (mg/dL) & $1.1 \pm 0.9$ & $1.0 \pm 0.6$ & 0.465 \\
\hline Albumin $(\mathrm{g} / \mathrm{dL})$ & $4.4 \pm 0.5$ & $4.3 \pm 0.4$ & 0.192 \\
\hline Platelet $\left(\times 10^{3} / \mathrm{mm}^{3}\right)$ & $183 \pm 73$ & $178 \pm 83$ & 0.713 \\
\hline HBeAg $(+)(n, \%)$ & $38(39.5)$ & $9(16.9)$ & 0.003 \\
\hline HBV DNA ( $\log _{10}$ copies/mL) & $2.7 \pm 2.8$ & $4.0 \pm 2.6$ & 0.008 \\
\hline Interval" (months) & $26 \pm 3$ & $27 \pm 8$ & 0.221 \\
\hline
\end{tabular}

Results are expressed in mean \pm SD or numbers (\%).

AST, aspartate aminotransferase; ALT, alanine aminotransferase; HBeAg, hepatitis B envelop antigen; HBV, hepatitis B virus.

${ }^{*}$ Time elapsed between the first and second liver stiffness examinations.

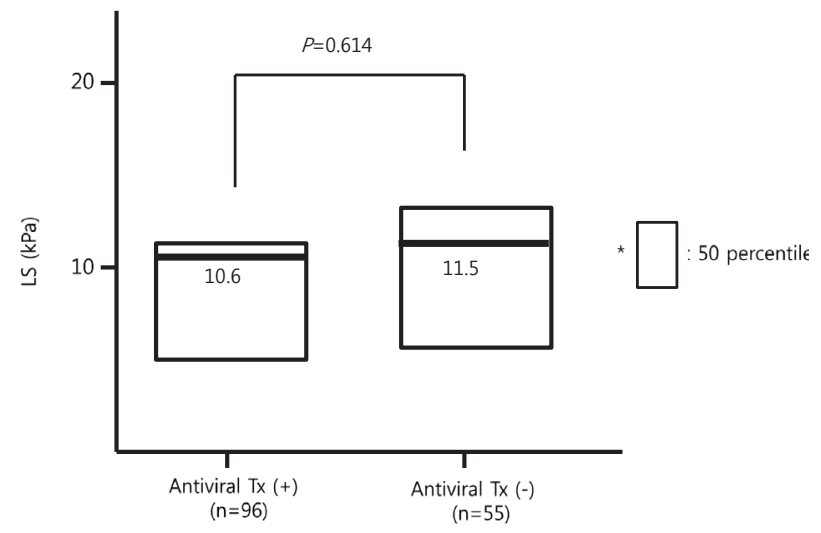

Figure 2. Comparison of initial liver stiffness values in the antiviral therapy $(+)$ and $(-)$ groups. The initial LS values were similar between the two groups.

sistance and then antiviral agents were changed during the study period.

\section{Initial LS values and LS changes}

Mean initial LS was $10.6 \mathrm{kPa}$ in the antiviral therapy (+) group and $11.5 \mathrm{kPa}$ in the antiviral therapy (-) group (Fig. 2), which was not a significant difference $(P=0.614)$. However, mean improvement in LS per year was higher in the antiviral therapy (+) group (-3.0 vs. $0.98 \mathrm{kPa}, P=0.011$ ) (Fig. 3). In the antiviral therapy (+) group, LS improved in 63 patients (65.6\%), whereas in the antivi-

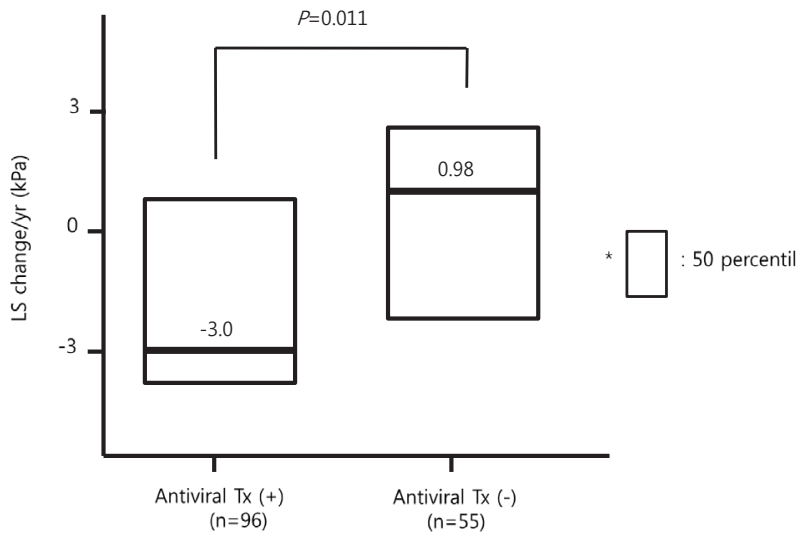

Figure 3. Comparison of the liver stiffness (LS) changes per year in the antiviral therapy (+) and (-) groups. LS improvement was greater higher in the antiviral therapy (+) group than between the antiviral therapy $(-)$ group.

ral therapy (-) group, LS improved in 29 patients (52.7\%). However, these improvement rates were not significantly different $(P=0.119)$.

\section{Patients' characteristics and LS value according to whether LS is improved or deteriorated in antiviral therapy $(+)$ group}

In antiviral therapy (+) group, 63 patients achieved an LS improvement and in 33 patients LS deteriorated. No differences were 
Table 2. Characteristics of the patients according to whether they exhibited an improved or deteriorated liver stiffness in the antiviral therapy (+) group

\begin{tabular}{|c|c|c|c|}
\hline & LS-improved $(n=63)$ & LS-deteriorated $(n=33)$ & $P$-value \\
\hline Age (years) & $49(28-63)$ & $47(31-66)$ & 0.702 \\
\hline Sex (male, \%) & $49(78)$ & $22(67)$ & 0.244 \\
\hline Initial LS (kPa) & $7.9(4.0-63.1)$ & $4.8(3.1-20.8)$ & $<0.001$ \\
\hline Liver cirrhosis (n, \%) & $21(33)$ & $7(21)$ & 0.207 \\
\hline AST (IU/L) & $27(16-89)$ & $26(15-59)$ & 0.547 \\
\hline $\mathrm{ALT}(\mathrm{IU} / \mathrm{L})$ & $28(9-74)$ & $28(7-60)$ & 0.714 \\
\hline Total bilirubin (mg/dL) & $0.9(0.4-8.2)$ & $0.9(0.4-3.1)$ & 0.281 \\
\hline Albumin (g/dL) & $4.5(2.6-5.0)$ & $4.4(2.6-4.9)$ & 0.634 \\
\hline Platelet $\left(\times 10^{3} / \mathrm{mm}^{3}\right)$ & $177(40-362)$ & $205(49-314)$ & 0.166 \\
\hline $\operatorname{HBeAg}(+)(n, \%)$ & $24(38)$ & $14(42)$ & 0.681 \\
\hline HBV DNA ( $\log _{10}$ copies/mL) & $2.2(0-8.6)$ & $2.2(0-9.0)$ & 0.624 \\
\hline Interval* (months) & $25(21-33)$ & $25(23-36)$ & 0.175 \\
\hline Maintained HBV DNA = 1000 copies $/ \mathrm{mL}(\mathrm{n}, \%)$ & $34(54)$ & $15(45)$ & 0.464 \\
\hline Maintained ALT = $40 \mathrm{IU} / \mathrm{L}(\mathrm{n}, \%)$ & $36(57)$ & $15(45)$ & 0.276 \\
\hline
\end{tabular}

Results are expressed in medians (ranges) or numbers (\%).

AST, aspartate aminotransferase; ALT, alanine aminotransferase; HBeAg, hepatitis B envelop antigen; HBV, hepatitis B virus; LS, liver stiffness.

*Time elapsed between the first LS and second LS examinations.

Table 3. Characteristics of the patients according to whether they exhibited an improved or deteriorated liver stiffness in the antiviral therapy (-) group

\begin{tabular}{|c|c|c|c|}
\hline & LS-improved ( $n=29)$ & LS-deteriorated $(n=26)$ & $P$-value \\
\hline Age (years) & $48(33-71)$ & $51(33-72)$ & 0.774 \\
\hline Sex (male, \%) & $15(52)$ & $19(73)$ & 0.101 \\
\hline Initial LS (kPa) & $8.3(4.8-65.3)$ & $6.5(2.8-17.3)$ & 0.021 \\
\hline Liver cirrhosis (n, \%) & $10(34)$ & $10(38)$ & 0.759 \\
\hline AST (IU/L) & $30(18-58)$ & $28(16-75)$ & 0.394 \\
\hline ALT (IU/L) & $30(9-70)$ & $30(14-72)$ & 0.625 \\
\hline Total bilirubin (mg/dL) & $0.9(0.5-3.3)$ & $0.8(0.3-2.0)$ & 0.374 \\
\hline Albumin (g/dL) & $4.4(3.1-4.9)$ & $4.3(3.1-4.8)$ & 0.402 \\
\hline Platelet $\left(\times 10^{3} / \mathrm{mm}^{3}\right)$ & $142(21-342)$ & $171(41-349)$ & 0.972 \\
\hline HBeAg $(+)(n, \%)$ & $3(10)$ & $6(23)$ & 0.243 \\
\hline HBV DNA ( $\log _{10}$ copies/mL) & $3.5(0-9.5)$ & $3.5(0-9.5)$ & 0.690 \\
\hline Interval (months) ${ }^{*}$ & $28(20-63)$ & $26(14-50)$ & 0.098 \\
\hline Maintained HBV DNA=1000 copies/mL (n, \%) & $7(24)$ & $10(38)$ & 0.251 \\
\hline Maintained ALT=40 IU/L (n, \%) & $16(55)$ & $8(31)$ & 0.067 \\
\hline
\end{tabular}

AST, aspartate aminotransferase; ALT, alanine aminotransferase; HBeAg, hepatitis B envelop antigen; HBV, hepatitis B virus; LS, liver stiffness.

"Time elapsed between the first LS and second LS examinations.

found in the clinical characteristics and laboratory data between LS-improved and LS-deteriorated group (Table 2).

Median LS value at first TE was higher in LS-improved than in LS-deteriorated group (7.9 vs. $4.8 \mathrm{kPa}, P<0.001$ ). The proportions of patients who maintained a HBV DNA level below 1000 copies/
$\mathrm{mL}$ or a normal ALT level ( $\leq 40 \mathrm{IU} / \mathrm{L})$ during the study period were similar in these two groups (Table 2). The median changes of LS in patients with or without maintained HBV DNA level below 1000 copies $/ \mathrm{mL}$ were -1.95 and $-0.4 \mathrm{kPa}$ respectively $(P=0.480)$. 


\section{Patients' characteristics and LS value according to whether LS is improved or deteriorated in antiviral therapy (-) group}

In the antiviral therapy (-) group, 29 patients achieved an LS improvement and in 26 patients $\mathrm{LS}$ deteriorated. No differences were found in the clinical characteristics and laboratory data between LS-improved and LS-deteriorated group (Table 3).

Median LS value at first TE was higher in LS-improved than in LS-deteriorated group (8.3 vs. $6.5 \mathrm{kPa}, P=0.021$ ). The proportions of patients who maintained a HBV DNA level below 1000 copies/ $\mathrm{mL}$ during the study period were similar in these two groups. However, the proportion of patients who maintained a normal ALT level $(\leq 40 \mathrm{IU} / \mathrm{L})$ during the study period was slightly higher in LSimproved group (55\% vs. 31\%, $P=0.067$ ) (Table 3 ).

\section{Multivariate analysis and the factors that improved LS}

Variables that had $P$-value less than 0.1 in univariate analysis and factors about treatment response such as maintained HBV DNA $\leq 1000$ copies/mL and maintained $A L T \leq 40 \mathrm{IU} / \mathrm{L}$, were used for multivariate analysis. Only a higher initial LS value was found to be significantly associated with LS improvement in the antiviral therapy (+) group [odd ratio (OR): 1.186, 95\% confidence interval (CI): 1.048-1.342, $P=0.007$ ], and tended to be associated with LS improvement in antiviral therapy (-) group (OR: 1.114, 95\% Cl: 0.997-1.244, $P=0.056$ ).

\section{DISCUSSION}

Many authors have concluded that liver fibrosis can be reversed if the underlying cause of liver disease is removed. In CHC, the achievement of sustained virologic response (SVR) by interferon (INF) lowered the rate of fibrosis progression. ${ }^{19}$ In a long-term HCV study, fibrosis was improved in the majority patients, and even cirrhosis could be reversed in patients with SVR by INF-based therapy. ${ }^{20-23}$ Similar results were observed using LS measurements in CHC patients treated with INF-based therapy, that is, patients with SVR showed a significant reduction in LS versus those without SVR. ${ }^{24,25}$

$\mathrm{HBV}$ is rarely eradicated by antiviral treatment, but the sustained suppression of HBV replication can improve liver disease from the perspectives of blood chemistry and histology. ${ }^{26}$ Long-term treatment with LAM achieved improvements of histology in $\mathrm{HBeAg}+\mathrm{ve}$ and HBeAg-ve patients, and even cirrhosis patients. ${ }^{27,28}$ However, long-term therapy with LAM can result in the development of resistance, and patients who developed resistance showed greater disease progression than those that did not develop resistance. ${ }^{27}$ Unlike LAM, ETV and tenofovir have low resistance rates. In ETV and tenofovir studies, the majority of patients treated with ETV or tenofovir showed significant improvements in liver histology and Ishak fibrosis scores. ${ }^{29-31}$ These studies demonstrate that regression of fibrosis is possible if HBV replication is successfully inhibited during long-term antiviral therapy. In a study on the use of LS measurements to evaluate changes in fibrosis, LS values significantly improved in CHB patients treated with ETV for 12 months. ${ }^{2}$ In the present study, although several types of oral antiviral agents were used, LS significantly improved after about 2 years of antiviral therapy. Although 24 cases of drug resistance occurred during the study period, the institution of rapid rescue therapy prevented LS deterioration.

In the present study, 55 patients did not receive antiviral therapy due to a low viral load or a low ALT level in accord with the requirements of the Korea National Health Insurance. Thirty-nine of these patients had a low HBV DNA and a low ALT level (data not shown), and 16 had a high HBV DNA but a low ALT level (data not shown). These patients was inhomogeneous in terms of natural history of chronic HBV infection. ${ }^{26}$ Some of our patients might have been in the immune tolerance phase, and others might have been inactive HBV carriers or in the active state. Furthermore, because no liver biopsy was performed in most of our patients, analyses by disease status were not possible. Generally speaking, these patients were expected to remain in a stable disease state with respect to fibrosis, because they had a stable HBV DNA or ALT level during the study period. However, our antiviral therapy (-) group had a mean LS deterioration of 0.98/year.

Only limited data is available on the natural course of CHB patients during the stable disease state. Contrary to the general perception that fibrosis does not progress during the stable disease state, we found that liver fibrosis showed a tendency to progress. However, as no pathologic diagnosis was performed in the present study, it was not known whether these patients were really in a stable state or not. Therefore, further study is needed to determine which patients show fibrosis progression by liver biopsy and which patients in the stable disease state benefit from antiviral therapy.

Although LS is a physical parameter that is mainly associated with fibrosis, it is also affected by other factors that influence liver elasticity, such as, inflammation, edema, and vascular conges- 
tion. ${ }^{32-36}$ In previous reports, LS was found to be affected by serum levels of total bilirubin, ALT, gamma-glutamyl transpeptidase, platelet count, albumin, international normalized ratio, and old age. ${ }^{110,11,37}$ Among these, serum ALT level was found to most importantly affect LS, more specifically, LS value and ALT levels were found to be positively related. ${ }^{32,38}$ Therefore, LS values should be cautiously interpreted when serum ALT is elevated. In the present study, patients with an ALT level $>80 \mathrm{IU} / \mathrm{mL}$ were excluded to prevent ALT values affecting results.

By univariate analysis, a higher baseline LS value was significantly associated with an annual LS improvement in anti-viral therapy treated and untreated patients. By multivariate analysis, a higher baseline $L S$ value was a significant factor only in the antiviral therapy (+) group, but a marginal association was observed in the antiviral therapy (-) group. Few reports are available on factors that improve LS in patients with chronic hepatitis. In one report, a higher LS value was found to be associated with a significant improvement in LS in patients with CHC treated with an INF-based therapy. ${ }^{25,39}$ In addition, a higher initial LS value was also found to be a significantly associated with an LS improvement in CHB patients treated with oral antiviral agents. ${ }^{17} \mathrm{~A}$ high initial LS value might be the result of elevated necroinflammatory activity, and more significant reductions in LS values were observed in the patients with an initial high LS value after the resolution of inflammatory activity. ${ }^{17,25,39}$ However, we excluded patients with an ALT level exceeding $80 \mathrm{IU} / \mathrm{L}$, and therefore, the influence of ALT level on $L S$ value was reduced in the present study. Therefore, LS value in this study is more convincing compared to previous studies. Further large scale studies using LS examinations and liver biopsy are required to prove this result.

Fung et al. ${ }^{17}$ performed a study with a 3-year follow-up on 316 untreated CHB patients, and reported only patients that maintained ALT within the normal range during the study period achieved an LS improvement. However, in the present study, the maintenance of a normal ALT level during the study period was not found to be associated with LS improvement. In the antiviral therapy (+) group, antiviral agents successfully suppressed ALT in most patients. Furthermore, even when antiviral resistance developed and ALT increased, the implementation of rapid rescue therapy suppressed further ALT increases. In the antiviral therapy (-) group, ALT did not increase high enough to influence LS values. Forty-one patients that did not meet insurance guidelines at first TE, later showed an ALT level increase and received antiviral therapy during the study period (Fig. 1A). However, these patients were excluded as mentioned previously. Therefore, the mainte- nance of a normal ALT level may not have been a significant factor of LS improvement in the antiviral therapy (-) group.

In the present study, a sustained low HBV DNA level was not associated with LS improvement. In the antiviral therapy (+) group, antiviral agents had suppressed serum HBV DNA level at first TE, and thus, further decreases in HBV DNA or a sustained low level of HBV DNA may not have effected LS improvements. Furthermore, as mentioned above, even when antiviral resistance developed, rapid rescue therapy suppressed further HBV DNA elevation and biochemical breakthrough. In the antiviral therapy (-) group, the majority of patients had a sustained low HBV DNA level during the study period. Thirty-nine of these 55 patients (71\%) had a HBV DNA level of $<10,000$ copies/mL throughout the study period, and thus, a sustained low level of HBV DNA could not influence LS improvements.

Some limitations of the study warrant consideration. First, the effect of antiviral therapy on $L S$ improvement would be best assessed by dividing the study population into antiviral treated and untreated groups, but this presents moral issues. Accordingly, we separately analyzed an antiviral therapy (+) group that satisfied the insurance guidelines and an antiviral therapy (-) group that did not, and despite separate analyses, a higher initial LS was found to be a common factor for $\mathrm{LS}$ improvement by univariate analysis. Second, paired liver biopsies are needed to estimate improvements in fibrosis. However, this procedure is not permitted in CHB patients with stable disease, and patients on antiviral therapy are unwilling to undergo paired liver biopsy.

In conclusion, the only factor found to be associated with LS improvement in CHB patients with antiviral therapy and in patients with stable disease state for about 2 years was a higher initial LS value. Despite serial checking ALT and HBV DNA levels at multiple time points, the maintenance of a normal ALT level and a sustained low HBV DNA level were not found to be significantly associated with $L S$ improvement. However, this result can apply only to CHB patients with successful antiviral therapy or with stable disease state. A further, large scale, liver biopsy and TE based study is needed to identify factors that improve LS.

\section{Conflicts of Interest}

The authors have no conflicts to disclose.

\section{REFERENCES}

1. Kim SU, Park JY, Kim do Y, Ahn SH, Choi EH, Seok JY, et al. Non-inva- 
sive assessment of changes in liver fibrosis via liver stiffness measurement in patients with chronic hepatitis B: impact of antiviral treatment on fibrosis regression. Hepatol Int 2010;4:673-680.

2. Enomoto M, Mori M, Ogawa T, Fujii H, Kobayashi S, Iwai $S$, et al. Usefulness of transient elastography for assessment of liver fibrosis in chronic hepatitis B: Regression of liver stiffness during entecavir therapy. Hepatol Res 2010;40:853-861.

3. Arase Y, Ikeda K, Suzuki F, Suzuki Y, Saitoh S, Kobayashi M, et al. Long-term outcome after hepatitis $B$ surface antigen seroclearance in patients with chronic hepatitis B. Am J Med 2006;119:71. e9-16.

4. Chen YC, Sheen IS, Chu CM, Liaw YF. Prognosis following spontaneous HBsAg seroclearance in chronic hepatitis B patients with or without concurrent infection. Gastroenterology 2002;123:1084-1089.

5. Perrault J, McGill DB, Ott BJ, Taylor WF. Liver biopsy: complications in 1000 inpatients and outpatients. Gastroenterology 1978;74:103-106.

6. Janes $\mathrm{CH}$, Lindor KD. Outcome of patients hospitalized for complications after outpatient liver biopsy. Ann Intern Med 1993;118:96-98.

7. Rockey DC, Bissell DM. Noninvasive measures of liver fibrosis. Hepatology 2006:43(2 Suppl 1):S113-120.

8. Halfon P, Bacq Y, De Muret A, Penaranda G, Bourliere M, Ouzan D, et al. Comparison of test performance profile for blood tests of liver fibrosis in chronic hepatitis C. J Hepatol 2007;46:395-402.

9. Yoshioka K, Kawabe N, Hashimoto S. Transient elastography: Applications and limitations. Hepatol Res 2008;38:1063-1068.

10. Castera L, Forns $X$, Alberti A. Non-invasive evaluation of liver fibrosis using transient elastography. J Hepatol 2008;48:835-847.

11. Sandrin L, Fourquet B, Hasquenoph JM, Yon S, Fournier C, Mal F, et al. Transient elastography: a new noninvasive method for assessment of hepatic fibrosis. Ultrasound Med Biol 2003;29:1705-1713.

12. Zhang YG, Wang BE, Wang TL, Ou XJ. Assessment of hepatic fibrosis by transient elastography in patients with chronic hepatitis $B$. Pathol Int 2010;60:284-290.

13. Castera L, Vergniol J, Foucher J, Le Bail B, Chanteloup E, Haaser M, et al. Prospective comparison of transient elastography, Fibrotest, APRI, and liver biopsy for the assessment of fibrosis in chronic hepatitis $C$. Gastroenterology 2005;128:343-350.

14. Colletta C, Smirne C, Fabris C, Toniutto P, Rapetti R, Minisini R, et al. Value of two noninvasive methods to detect progression of fibrosis among HCV carriers with normal aminotransferases. Hepatology 2005;42:838-845.

15. Ziol M, Handra-Luca A, Kettaneh A, Christidis C, Mal F, Kazemi F, et al. Noninvasive assessment of liver fibrosis by measurement of stiffness in patients with chronic hepatitis C. Hepatology 2005;41:48-54.

16. Corpechot C, El Naggar A, Poujol-Robert A, Ziol M, Wendum D, Chazouillères $\mathrm{O}$, et al. Assessment of biliary fibrosis by transient elastography in patients with PBC and PSC. Hepatology 2006;43:11181124.

17. Fung J, Lai CL, Wong DK, Seto WK, Hung I, Yuen MF. Significant changes in liver stiffness measurements in patients with chronic hepatitis B: 3-year follow-up study. J Viral Hepat 2011;18:e200-5.

18. Suk KT, Baik SK, Yoon JH, Cheong JY, Paik YH, Lee CH, et al. Revision and update on clinical practice guideline for liver cirrhosis. Korean J Hepatol 2012;18:1-21.

19. Poynard T, McHutchison J, Manns M, Trepo C, Lindsay K, Goodman Z et al. Impact of pegylated interferon alfa-2b and ribavirin on liver fibrosis in patients with chronic hepatitis C. Gastroenterology 2002;122:13031313.

20. George SL, Bacon BR, Brunt EM, Mihindukulasuriya KL, Hoffmann J, Di Bisceglie AM. Clinical, virologic, histologic, and biochemical outcomes after successful HCV therapy: a 5-year follow-up of 150 patients. Hepatology 2009:49:729-738.

21. Veldt BJ, Heathcote EJ, Wedemeyer H, Reichen J, Hofmann WP, Zeuzem S, et al. Sustained virologic response and clinical outcomes in patients with chronic hepatitis $C$ and advanced fibrosis. Ann Intern Med 2007; 147:677-684

22. Bruno S, Stroffolini T, Colombo M, Bollani S, Benvegnù L, Mazzella G, et al. Sustained virological response to interferon-alpha is associated with improved outcome in HCV-related cirrhosis: a retrospective study. Hepatology 2007:45:579-587.

23. Maylin S, Martinot-Peignoux M, Moucari R, Boyer N, Ripault MP, Cazals-Hatem $D$, et al. Eradication of hepatitis $C$ virus in patients successfully treated for chronic hepatitis C. Gastroenterology 2008;135:821829.

24. Arima Y, Kawabe N, Hashimoto S, Harata M, Nitta Y, Murao M, et al. Reduction of liver stiffness by interferon treatment in the patients with chronic hepatitis C. Hepatol Res 2010;40:383-392.

25. Wang JH, Changchien CS, Hung CH, Tung WC, Kee KM, Chen CH et al. Liver stiffness decrease after effective antiviral therapy in patients with chronic hepatitis C: Longitudinal study using FibroScan. J Gastroenterol Hepatol 2010;25:964-969.

26. EASL clinical practice guidelines: Management of chronic hepatitis $B$ virus infection. J Hepatol 2012;57:167-185.

27. Dienstag JL, Goldin RD, Heathcote EJ, Hann HW, Woessner M, Stephenson $\mathrm{SL}$, et al. Histological outcome during long-term lamivudine therapy. Gastroenterology 2003;124:105-117.

28. Rizzetto M, Tassopoulos NC, Goldin RD, Esteban R, Santantonio T, Heathcote EJ, et al. Extended lamivudine treatment in patients with HBeAg-negative chronic hepatitis B. J Hepatol 2005;42:173-179.

29. Chang TT, Liaw YF, Wu SS, Schiff E, Han KH, Lai CL, et al. Long-term entecavir therapy results in the reversal of fibrosis/cirrhosis and continued histological improvement in patients with chronic hepatitis B. Hepatology 2010;52:886-893.

30. Schiff ER, Lee SS, Chao YC, Kew Yoon S, Bessone F, Wu SS, et al. Longterm treatment with entecavir induces reversal of advanced fibrosis or cirrhosis in patients with chronic hepatitis B. Clin Gastroenterol Hepatol 2011;9:274-276. 
31. Marcellin P, Gane E, Buti M, Afdhal N, Sievert W, Jacobson IM et al. Regression of cirrhosis during treatment with tenofovir disoproxil fumarate for chronic hepatitis B: a 5-year open-label follow-up study. Lancet 2013;381:468-475.

32. Coco B, Oliveri F, Maina AM, Ciccorossi P, Sacco R, Colombatto P, et al. Transient elastography: a new surrogate marker of liver fibrosis influenced by major changes of transaminases. J Viral Hepat 2007;14:360 369.

33. Oliveri F, Coco B, Ciccorossi P, Colombatto P, Romagnoli V, Cherubini $B$, et al. Liver stiffness in the hepatitis $B$ virus carrier: a non-invasive marker of liver disease influenced by the pattern of transaminases. World J Gastroenterol 2008;14:6154-6162.

34. Arena U, Vizzutti F, Corti G, Ambu S, Stasi C, Bresci S, et al. Acute viral hepatitis increases liver stiffness values measured by transient elastography. Hepatology 2008;47:380-384.
35. Sagir A, Erhardt A, Schmitt M, Häussinger D.. Transient elastography is unreliable for detection of cirrhosis in patients with acute liver damage. Hepatology 2008:47:592-595.

36. Roulot D, Czernichow S, Le Clésiau H, Costes JL, Vergnaud AC, Beaugrand M. Liver stiffness values in apparently healthy subjects: influence of gender and metabolic syndrome. J Hepatol 2008;48:606-613.

37. Bae RC, Cho HJ, Oh JT, Lee EK, Heo J, Shin KY, et al. Clinical factors influencing liver stiffness as measured by transient elastography (Fibroscan) in patients with chronic liver disease. Korean J Hepatol 2010;16:123-130.

38. Seo YS. Transient elastography, true or false? Korean J Hepatol 2009;15:431-437.

39. Martinez SM, Foucher J, Combis JM, Métivier S, Brunetto M, Capron $D$, et al. Longitudinal liver stiffness assessment in patients with chronic hepatitis C undergoing antiviral therapy. PloS one 2012;7:e47715. 